\title{
Relações entre Proeminência Facial nas Fotos do Orkut e o Perfil dos Usuários
}

\author{
Viviane Vedovato Pereira da Silva ${ }^{* a}$, Sandro Caramaschi ${ }^{a}$ \& Maria Márcia Pereira Sartori ${ }^{b}$ \\ ${ }^{a}$ Universidade Estadual Paulista Júlio de Mesquita Filho, Bauru, Brasil \& ${ }^{\mathbf{b}}$ Faculdade de Tecnologia de Bauru, Bauru, Brasil
}

\begin{abstract}
RESUMO
Esta pesquisa teve como objetivo verificar a existência de relação entre o índice de proeminência facial (IPF) e o perfil de 600 usuários do Orkut. Os resultados mostraram que, em todos os segmentos avaliados, a média do IPF masculino foi superior ao feminino; as mulheres aumentam a proeminência enquanto os homens diminuem com a idade e mulheres com ensino superior apresentam maior proeminência do que as de ensino médio. Diferenças significativas também foram encontradas nas categorias de humor ao comparar o IPF entre os sexos e entre pessoas de mesmo sexo. Em síntese, os resultados indicam que fatores determinantes do IPF apresentado no Orkut provavelmente estão relacionados tanto a aspectos biológicos como culturais.
\end{abstract}

Palavras-chave: percepção facial; comunicação não verbal; internet; diferenças sexuais.

\begin{abstract}
Relationship Between Facial Prominence of Orkut's Photos and the Users' Profile

This research aimed to verify the relation between facial prominence index (FPI) and the profile of 600 users of Orkut. The results demonstrated that in all evaluated segments the average of male facial prominence was higher than the female; women increase the prominence while men decrease it as they become older and university graduates women have presented higher prominence than high school graduates. Significant differences were also found in the categories of humor when comparing the FPI between the genders and between persons of the same gender. In summary, the results indicate that the determinant factors for the facial prominence presented at Orkut are probably related to both biological and cultural aspects.
\end{abstract}

Keywords: facial perception; nonverbal communication; internet; sex differences.

A capacidade de emitir e codificar informações são fatores inquestionáveis para a sobrevivência de muitas espécies, inclusive a humana. Pode-se dizer que a comunicação é o elo que estabelece o vínculo entre as pessoas, vínculo este importante nas relações humanas devido a uma necessidade básica do indivíduo em compartilhar com os demais suas ideias, valores, crenças e gostos (Knapp \& Hall, 1999). Este compartilhar se processa tanto em nível verbal quanto nãoverbal. A comunicação verbal consiste na utilização de palavras e signos linguísticos, proporcionando a difusão de informações de modo mais objetivo. A comunicação não verbal, por outro lado, compreende a movimentação corporal - expressões faciais, postura, gestos - o toque, artefatos usados pelo homem, a distância mantida entre as pessoas e o uso do seu espaço pessoal (Silva, Silva, \& Menezes, 2006).

Diversos autores se preocuparam em compreender como se processa a utilização do espaço pessoal em diferentes contextos. Campos e Gomes (2009), por exemplo, investigaram as marcas deixadas pelos diferentes tipos de comportamento que a corporeidade de pessoas comuns apresenta quando estão ocupando locais públicos. Os resultados mostraram que há uma comunicação não verbal que fala o tempo todo, seja no ato de vestir, na expressão dura do rosto, na insatisfação durante os transportes coletivos, no desconforto da poluição sonora e visual, no isolamento individual

* Endereço para correspondência: Viviane Vedovato Pereira da Silva: vivi_vedovato@hotmail.com 
em meio à multidão de pessoas que superlotam os espaços públicos, os meios de transportes, etc. Apesar de algumas pessoas apresentarem diferenças visíveis quanto à situação financeira, no modo de ir e vir, no modo de ser, vestir, falar, ler, divertirem-se e ocupar esses lugares, elas se assemelham em seu comportamento etológico. Desta forma, o trabalho pode observar que os seres humanos comportam-se de maneira parecida nesses espaços para produzir uma acomodação necessária no fato de pertencer a um determinado grupo social. Para Knapp \& Hall (1999), a utilização do espaço pessoal depende do grau de intimidade entre as pessoas, do local em que está inserido, do número de pessoas no ambiente, a situação em andamento, etc. Portanto, esse processo influenciará na maneira como o indivíduo estabelecerá uma distância específica com relação aos demais.

Em 1989, o antropólogo Edward Hall já se preocupava com o estudo da estruturação inconsciente do microespaço humano, denominado proxêmica. Os resultados de suas pesquisas permitiram que este pesquisador estabelecesse quatro distâncias individuais básicas - íntima, pessoal, social e pública - cada uma delas subdividida em uma fase próxima e outra distante. Considerando essas distâncias, verificaram-se componentes relacionados com o impacto emocional e grau de intimidade, percebidos por meio das sensações odoríferas, visuais e auditivas (Caramaschi, 1997). Assim como o uso do espaço pessoal e a distância mantida entre as pessoas na interação social, o indivíduo também pode estabelecer diferentes distâncias em relação a um objeto como, por exemplo, uma câmera fotográfica. E, da mesma forma que a distância entre duas pessoas interfere na transmissão de informações sensoriais, estudos mostram que o enquadramento da câmera interfere na proporção em que a pessoa se apresenta em uma fotografia, produzindo diferentes avaliações acerca de características não verbais.

Archer, Iritani, Kimes e Barrios (1983) foram pioneiros neste tipo de estudo com base no qual desenvolveram o Índice de Proeminência Facial (IPF). Este índice envolve a relação entre duas medidas, uma divisão, na qual o numerador correspondente à distância entre o topo da cabeça até o ponto mais inferior do queixo e, o denominador referente à distância entre o topo da cabeça até a parte mais inferior do corpo retratado. Os resultados de suas pesquisas indicaram a retratação dos homens com maior proporção do rosto - enquadramento mais próximo - do que as mulheres. Uma alta proporção facial foi avaliada, por diferentes pessoas, como indicadoras de dominância, enquanto baixos índices de proporção facial foram avaliados como indicadoras de cordialidade. Isto contribuiu para a possibilidade de que os homens sejam identificados por qualidades cerebrais ou mentais, enquanto as mulheres por qualidades emocionais ou corporais.

Dando continuidade aos trabalhos de Archer e cols. (1983), Zuckerman (1986) realizou uma nova série de pesquisas, baseada em três estudos dentre os quais apenas dois serão citados. No primeiro estudo, 912 fotografias de seis publicações americanas foram selecionadas, três delas identificadas como edições femininas (Ms., Working Woman, e Rochester Women) e três mais tradicionais (Time, Newsweek, e US News and World Report). Os resultados mostraram que a diferença entre gêneros, com relação à Proeminência Facial, é menos discrepante em revistas relacionadas a assuntos femininos do que nos periódicos tradicionais. Zuckerman (1986) levanta a hipótese da visão tradicional dos papéis conferidos a cada gênero transmitir uma mensagem específica levando-se em conta a proeminência facial. O papel masculino está associado a características como eficácia, instrumentalidade e controle, enquanto que o feminino se caracteriza por expressividade, solidariedade e sensibilidade interpessoal. Desta forma, um alto índice de proeminência facial, verificado na pesquisa de Zuckerman (1986) em fotos masculinas, transmite impressões de maior dominância, controle, inteligência, ambição e atração. A cordialidade e a sensibilidade, características atribuídas como femininas, foram relacionadas a um baixo nível de proeminência facial. A atribuição de dominância para uma alta proeminência facial está baseada na utilização, de acordo com Zuckerman e Kieffer (1994), da palavra face que implica um significado de confronto.

Para o segundo estudo (Zuckerman, 1986), foram tiradas duas fotos de 48 pessoas, metade homens e metade mulheres, uma com baixo índice de proeminência facial e a outra com um índice alto. Essas fotografias foram julgadas acerca da dominância e positividade por universitários, utilizando uma escala de 1 a 7 pontos. A dimensão da dominância era representada pelos adjetivos dominante ou tímido, assertivo ou frágil, já a dimensão positividade por cordial ou hostil, legal ou frio. Verificou-se relação significativa entre alta proeminência facial e dominância, quando as subescalas dominância e positividade eram analisadas separadamente. Quando esses fatores foram combinados, a associação entre alta proeminência facial e menor positividade também foi significativa. Estes resul- 
tados apoiam a hipótese de uma associação entre masculinidade e dominância, e entre feminilidade e positividade, isto é, cordialidade.

Estudos posteriores geraram resultados consistentes que ajudaram a confirmar a presença generalizada do fenômeno da proeminência facial. Por exemplo, Nigro, Hill, Gelbein e Clark (1988) observaram o fenômeno da diferença de proeminência facial em revistas de notícias e revistas femininas referentes aos anos de 1970 e 1980. Bretl e Cantor (1988) sustentaram que a percepção da autoridade, credibilidade, confiança, competência e até mesmo a constituição física do indivíduo também podem ser afetados pela proeminência facial. Do mesmo modo, Copeland (1989) documentou a proeminência facial em programas de televisão no horário nobre. Outros autores que se preocuparam em explorar o impacto da proeminência facial na formação de impressões foram Schwarz e Kurz (1989). O estudo utilizou fotografias de corpo inteiro e da parte superior do corpo de 87 pessoas do sexo masculino e 84 do sexo feminino, da Alemanha Ocidental e com idades entre 14 e 17 anos. Estas fotografias foram feitas a partir dos mesmos negativos e da mesma pessoa estímulo. Os resultados mostraram que os sujeitos avaliaram como mais competentes inteligentes, assertivos, ambiciosos - todas as pessoas que apresentaram um alto (retrato), em vez de um baixo (fotografia de corpo inteiro), grau de proeminência facial. Assim, o face-ism da mídia é suscetível a contribuir para uma percepção dos homens como mais competentes do que as mulheres.

Matthews (2007) forneceu evidências de que a proeminência facial ainda está presente nos principais meios de comunicação impressa até o ano de 2004, e mostrou que os homens nas profissões intelectualmente focadas tendem a ter maior proeminência facial do que as mulheres em profissões semelhantes, enquanto as mulheres que trabalham na área de ciências exatas tendem a ter maior proeminência facial do que os homens em cargos semelhantes. Szillis e Stahlberg (2007), por meio de duas análises de conteúdo, buscaram explorar se há diferentes representações sobre os gêneros masculino e feminino na internet. O primeiro estudo comparou fotos, disponíveis na internet, de professores universitários do sexo feminino e masculino de doze diferentes universidades alemãs. O segundo estudo examinou imagens da internet de membros femininos e masculinos do parlamento alemão. Os resultados de ambos os estudos mostram que tanto os professores quanto políticos do sexo masculino são retratados com maior proeminência do que professoras e políticas do sexo feminino. Além disso, os polí- ticos mais jovens do sexo feminino são retratados com menor proeminência do que os políticos mais velhos também do sexo feminino, enquanto os políticos do sexo masculino são representados com maior proeminência, independentemente da sua idade. Segundos os autores, estas análises mostram a existência de uma assimetria consistente nas imagens de ambos os sexos, mostrando que a proeminência facial (mesmo depois de vinte anos das pesquisas de Archer, 1983) ainda está relacionada com o sexo, mesmo que os papéis sociais de mulheres e homens não tenham se mantido constantes. Complementam ainda que a proeminência facial é um fenômeno socialmente aprendido, sugerindo que há uma associação estereotipada da cabeça ou rosto com o intelecto ou masculinidade e a feminilidade com o corpo.

Apesar de a internet ser um meio de comunicação recente, ela não está livre da visão de gênero historicamente construída. E, embora as diferenças relatadas sejam pequenas, Szillis e Stahlberg (2007) apontam a possibilidade de essas diferenças contribuírem, direta ou indiretamente, para a manutenção do estereótipo da imagem da mulher como menos competentes do que os homens. Com base em três estudos, Konrath e Schwarz (2007) constataram - a partir da análise de fotografias de todos os governantes e senadores dos Estados Unidos, representantes e membros do parlamento do Canadá, Austrália e Noruega - que os políticos do sexo masculino são representados com maior proeminência facial do que os políticos do sexo feminino. Para congressistas americanas, a proeminência facial elevada está associada com um histórico de votação mais pró-feminista. Este estudo traz a seguinte contribuição: diferenças de gênero na proeminência facial não podem ser atribuídas às diferenças de gênero em proporções reais do corpo. Ainda que com algumas ressalvas, Konrath e Schwarz (2007) concluem que os resultados fornecem evidências preliminares de que políticos do sexo masculino de fato têm cabeças grandes, ou pelo menos, eles apresentam-se dessa forma.

No Brasil, a inexistência de pesquisas na área de proeminência facial fez com que Lapini e Caramaschi (2006) realizassem algumas investigações preliminares sobre a proporção facial. Na primeira etapa da pesquisa, foi medida a proporção facial de homens e mulheres em revistas nacionais de divulgação (Veja, Istoé e Época), direcionadas tanto para o público feminino quanto ao masculino. Os resultados apontaram uma superação de $11 \%$ na proporção facial masculina $(66 \%)$ em relação à feminina $(55 \%)$, reforçando a hipótese de que figuras masculinas estão fortemente associadas a qualidades mentais, ao poder cerebral e à 
razão, enquanto as femininas estão mais ligadas ao corpo, ao coração e à emoção. Em sua segunda fase, foi realizada uma avaliação experimental da percepção da proeminência facial por estudantes universitários de ambos os sexos. Foi criado um total de oito imagens, sendo quatro masculinas e quatro femininas; quatro com maior proporção facial $(\mathrm{IPF}=60 \%) \mathrm{e}$ quatro com menor proporção (IPF $=20 \%$ ). Essas fotos foram julgadas de acordo com 30 características emocionais apresentadas em um formulário de escalas de diferencial semântico. Das trinta características apresentadas no formulário, dez foram analisadas estatisticamente, quais sejam: conformismo, perigo, agressividade, coragem, gentileza, positividade, calma, produtividade, agrado e bondade. Somente "conformismo" e "perigo" tiveram resultados significativos no que diz respeito à proeminência facial; isto quer dizer que quanto mais longe, maior o conformismo; o contrário ocorre quanto mais perto a pessoa está. Com relação à característica "perigo", pode-se dizer que uma pessoa é considerada mais perigosa de perto do que de longe, isto é, conforme ocorre uma aproximação, o espaço do indivíduo vai sendo invadido e o invasor é considerado uma ameaça por estar próximo o suficiente para agredir a outra pessoa.

Quando se observa uma foto, o enquadramento utilizado pelo fotógrafo pode transmitir sensações de maior intimidade e proximidade psicológica no observador; tal recurso é amplamente utilizado por profissionais de propaganda comercial e, mais recentemente, na política (Caramaschi, 1997; Lima, 1988). Revistas que enfocam assuntos sobre política, por exemplo, tendem a divulgar imagens de senadores, deputados, presidentes e outros membros relacionados, com uma alta proeminência facial. O objetivo das revistas é aliar o conteúdo escrito com a imagem e as informações que esta transmite como, por exemplo, poder no caso de um político. Outro tipo frequente de imagem com alta proeminência facial é de um assassino. $\mathrm{O}$ rosto transmite uma sensação de periculosidade, sendo possível até observar os vasos sanguíneos dilatados da esclerótica. Geralmente, a revista divulga imagens no sentido de complementar ou chamar a atenção para a matéria escrita.

A grande maioria das pesquisas desenvolvidas na área de proeminência facial utiliza imagens produzidas por profissionais ou manipuladas experimentalmente para avaliação da percepção de observadores. Tais pesquisas demonstram aspectos culturais e sociais envolvidos na escolha de determinadas fotos a serem apresentadas ao público, caracterizando formas específicas de representar homens e mulheres. Até então, os estudos realizados sobre proeminência facial ficaram limitados aos desígnios de pessoas que direcionavam como a outra deveria ser fotografada, como e com quais intenções esta foto deveria ser apresentada ao público. Como seria o resultado da proeminência facial em fotografias em que a própria pessoa fotografada pudesse divulgá-las ou expô-las ao público?

O Orkut, rede social criada em janeiro de 2004 que visa ajudar seus membros a conhecer pessoas e manter relacionamentos, permite que seus usuários exponham diferentes tipos de informações pessoais, fotografias, vídeos, comunidades filiadas, lista de amigos, recados de amigos, etc. (Luccio \& Nicolaci-da-Costa, 2010). Um estudo preliminar foi desenvolvido por Mansur, Santos, Rimoldi, Silva, \& Caramaschi (2007), investigando como seriam os resultados quando as próprias pessoas têm a possibilidade de escolher suas fotografias a serem apresentadas publicamente. Desta forma, 150 fotografias de usuários disponíveis no Orkut - 75 de cada sexo - foram investigadas a fim de constatar possíveis diferenças entre gêneros com relação à proeminência facial. Através da análise dos resultados obtidos, verificou-se a existência de diferença significativa de aproximadamente $17 \%$, entre as médias da proeminência facial nas fotos de homens e mulheres. Esses dados reforçam a ideia apresentada nos estudos supracitados de que homens tendem a se apresentar mais próximos, enquanto as mulheres aparecem mais distantes nas fotografias.

Muitos autores têm se preocupado com a questão social envolvendo os meios de comunicação eletrônicos (Luccio \& Nicolaci-da-Costa, 2010). Para Honorato (2006), o uso em grande escala da internet, atraindo cada vez mais adeptos, foi alcançado a partir das tentativas de reproduzirem ao máximo a "sociedade real". De acordo com o autor, esta nova realidade gerada por esse novo meio de comunicação traz "transformações de relações, de encontros, de possibilidades afetivas e cognitivas" (p. 31). Atualmente, as relações sociais não mais se restringem à presença corporal, ter contato visual ou físico; o fator presencial parece não ser mais tão necessário no início de uma relação. Nicolaci-da-Costa (2005), após uma revisão de literatura, mostra que as tecnologias de telecomunicação interativas tornam possíveis diferentes tipos de contato interpessoal à distância em tempo real. Para a autora, a durabilidade das relações não deve ser atribuída somente à presença física de duas ou mais pessoas, uma vez que há a possibilidade das interações virtuais e ditas passageiras, transformarem-se em relacionamentos potencialmente tão duradouros quanto qualquer relacionamento "real". 
O cultivo da sociabilidade em ambientes virtuais é sustentado, para Dornelles (2004), tanto por uma base tecnológica quanto cultural, sendo essa adesão mais evidente entre as gerações jovens e de classe média, inferindo ainda que a prática da sociabilidade virtual mistura-se à vida cotidiana. Inserir-se em organizações com interesses em comum, gera no indivíduo um sentimento de pertencimento, bem como uma identidade cultural que, consequentemente, estará ligada a sua personalidade. De acordo com Ortiz (1999), a identidade individual foi ampliada pelo culturalismo para tornar-se identidade coletiva, pelo fato da cultura de um determinado grupo social ter uma função agregadora, limitada ao território físico da comunidade. A busca pelo coletivo é, atualmente, uma busca pela identificação entre as pessoas, como pode se verificar no Orkut, as pessoas interagem umas com as outras, estabelecendo indiretamente suas identidades.

Com base nos estudos apresentados, observa-se a crescente preocupação da esfera científica em compreender os diversos fenômenos embutidos nos meios de comunicação virtual. Ainda que haja diferentes possibilidades de análise, o presente artigo se restringe verificar o efeito da proeminência facial em um site específico de relacionamento, o Orkut. Os estudos evidenciam a relação entre proeminência facial e diferença de gêneros em meios de comunicação impressos, televisivos e virtuais. Em vista disso, o presente estudo buscou verificar se há diferença entre gêneros com relação à proeminência facial nas fotos de apresentação e o perfil dos usuários (faixa etária, humor e ensino) através das informações expostas no Orkut.

É importante enfatizar que pesquisar tal panorama significa dar conta de um fenômeno urbano atual, aproveitar a exequibilidade que o Orkut oferece para a coleta de dados, uma vez que as informações estão disponíveis ao público, bem como expandir novos conhecimentos científicos a respeito da interação social e comunicação não verbal mediada por computadores.

\section{MÉTODO}

\section{Material de Estudo}

Neste estudo, foi avaliada uma amostra de 600 contas de usuários do Orkut tanto do sexo feminino $(n=300)$ quanto do masculino $(n=300)$. Os elementos utilizados para análise foram, de maneira geral, as fotografias de apresentação e as informações do perfil geral (gênero), social (idade e humor) e profissional (grau de instrução).

\section{Procedimento}

A coleta dos dados ocorreu no primeiro semestre de 2009 e viabilizou-se com a abertura de uma conta de acesso ao Orkut, por meio da qual se tornou possível fazer a busca por usuários e seu respectivo perfil. Os critérios utilizados nesta pesquisa foram: ser brasileiro, heterossexual, afro-descendente ou caucasiano; ter idade entre 20 e 34 anos, grau de instrução entre fundamental e superior; apresentar pelo menos uma característica de humor e, exibir sua fotografia de apresentação. Para que não houvesse interferências nos resultados, algumas restrições foram necessárias como: excluir toda e qualquer foto de desenhos ou de crianças, levando em consideração apenas as fotos em que o usuário estava sozinho e sem "desejar" explicitamente destacar algum objeto, plano de fundo ou ação.

As fotografias de apresentação foram medidas na tela do computador com uma régua transparente de 15 $\mathrm{cm}$ e calculadas, em milímetros, por meio do Índice de Proeminência Facial elaborado por Archer e cols. (1983). Na presença de barba, franja, chapéu, boné ou qualquer outro elemento que dificultasse a delimitação exata do início da testa e do término do queixo, as medidas foram estimadas.

Com relação à variável idade, os usuários foram alocados dentro de três faixas etárias, a saber: 20 a 24 anos, 25 a 29 anos, e 30 a 34 anos, cada uma com amostras de tamanho $n=100$, definidas previamente. Optou-se por essas faixas etárias pelo fato de a maior população de usuários do Orkut no Brasil se situarem entre essas idades (Luccio \& Nicolaci-da-Costa, 2010).

O humor é dividido, pelo próprio Orkut, em sete categorias distintas: extrovertido/extravagante; inteligente/sagaz; misterioso; pateta/palhaço; rude; seco/sarcástico; simpático. O usuário pode optar por colocar quantas dessas categorias considerar compatíveis com seu humor. O perfil profissional do usuário mostra qual o seu grau de instrução dentre as seguintes opções: Ensino Fundamental, Ensino Médio, Superior Incompleto, Título de Tecnólogo, Diploma de Bacharel, Título de Mestre, Ph.D., Pós-Doutorado. Nesta pesquisa, estas opções foram condensadas da seguinte forma: Ensino Fundamental, Ensino Médio e Ensino Superior (representando desde o Superior Incompleto até o Pós-Doutorado).

\section{Tratamento dos dados}

Os dados foram organizados em duas páginas de registro elaboradas na planilha do Microsoft Excel, uma para o sexo feminino e outra para o masculino. 
Ambas continham o valor do IPF, faixa etária, categorias de humor e grau de instrução apresentados pelos usuários.

A Etapa I visou comparar o IPF segundo a faixaetária, humor e grau de instrução tanto intergênero quanto intragênero. Na Etapa II, comparou-se a média do IPF dentro de cada gênero avaliando se havia diferença significativa entre as pessoas que colocaram uma determinada categoria de humor com relação às que não colocaram esta categoria. Em ambas as etapas, não foram realizadas análises envolvendo interações entre as variáveis independentes. Para atingir estas comparações, os dados foram submetidos à análise estatística de variância univariada - ANOVA - e, complementados pelo Teste de Tukey através do aplicativo estatístico SigmaStat 2.0. Em todas as análises estatísticas foi adotado o nível de significância de $95 \%(p<0,05)$.

\section{RESULTADOS}

A análise de variância aplicada para comparação do IPF entre os sexos demonstrou uma diferença significativa $\left(F_{1,598}=16,247 ; p<0,001\right)$, conforme a Tabela 1. Apesar das médias do IPF masculino ser maior que o feminino em todas as faixas etárias avaliadas, a análise de variância revelou uma diferença significativa apenas entre 20 a $24 \operatorname{anos}\left(F_{1,198}=40,575 ; p<0,001\right)$.

Tabela 1

Comparação das Médias do Índice de Proeminência Facial (IPF) e Desvio Padrão da Variável Faixa Etária entre os Gêneros Feminino e Masculino

\begin{tabular}{ccccccc}
\hline \multirow{2}{*}{ FAIXA ETÁRIA } & FEMININO & & MASCULINO & \multicolumn{2}{c}{ Estatística } \\
\cline { 2 - 7 } & Média IPF & Desvio & Média IPF & Desvio & $\boldsymbol{F}$ & $\boldsymbol{p}$ \\
\hline $20-24$ & 0,5207 & 0,182 & 0,6861 & 0,182 & 40,575 & $<0,001^{*}$ \\
$25-29$ & 0,6076 & 0,201 & 0,6244 & 0,220 & 0,320 & 0,572 \\
$30-34$ & 0,6097 & 0,188 & 0,6217 & 0,185 & 0,207 & 0,650 \\
\hline TOTAL & 0,58 & 0,198 & 0,64 & 0,196 & 16,247 & $0,001^{*}$ \\
\hline
\end{tabular}

Nota. O número de usuários para cada faixa etária, em ambos os sexos, é 100.

${ }^{\text {a }}$ Os valores de $F$ correspondem à análise de variância.

* Valores significativos para $p<0,05$.

Outro dado importante que pode ser visto na Tabela 1 é o aumento da proeminência facial feminina enquanto se verifica a redução desta nos homens, conforme a idade vai aumentando. A análise de variância, aplicada para comparação estatística entre as faixas etárias em cada gênero, revelou uma diferença significativa entre 20-24 e 30-34 anos no grupo masculino $\left(F_{2,297}=3,438 ; p=0,033\right)$; entre $20-24$ e $25-29$ anos, assim como, entre 20-24 e 30-34 anos no sexo feminino $\left(F_{2,297}=7,018 ; p=0,001\right)$.

A Tabela 2 mostra como a proeminência facial se diferencia entre homens e mulheres de mesmo grau de instrução, evidenciando diferença significativa entre os gêneros no que concerne ao Ensino Médio ( $F$ $\left.{ }_{1,125}=6,662 ; p=0,011\right)$ e Ensino Superior $\left(F_{1,457}=8,658\right.$; $p=0,003)$.

Tabela 2

Comparação das Médias do Índice de Proeminência Facial (IPF) e Desvio Padrão da Variável Ensino entre os Gêneros Feminino e Masculino

\begin{tabular}{ccccccc}
\hline \multirow{2}{*}{ ENSINO } & FEMININO & \multicolumn{2}{c}{ MASCULINO } & \multicolumn{2}{c}{ Estatística } \\
\cline { 2 - 7 } & Média IPF & N & Média IPF & N & F & p \\
\hline Fundamental & 0,4490 & 8 & 0,6138 & 6 & 1,822 & 0,202 \\
Médio & 0,5295 & 64 & 0,6220 & 63 & 6,662 & $0,011^{*}$ \\
Superior & 0,5978 & 228 & 0,6509 & 231 & 8,658 & $0,003^{*}$ \\
\hline
\end{tabular}

Nota. Os valores de $F$ correspondem à análise de variância.

* Valores significativos para $p<0,05$.

Percebe-se que a diferença entre as médias diminui ao passo que o grau de instrução aumenta entre homens e mulheres. Nota-se também que, tanto no grupo feminino quanto no masculino, o índice aumenta de acordo com o maior nível de instrução. A análise de variância aplicada dentro de cada gênero mostrou 
diferença significativa apenas entre o grupo das mulheres $\left(F_{2,297}=5,002 ; p=0,007\right)$ no que se refere ao ensino médio e superior.
A última variável considerada na Etapa I foi o humor, na qual os homens tiveram IPF maior que as mulheres em todas as categorias. A análise de variância aplicada às categorias de humor revelou diferença significativa entre os gêneros, segundo a Tabela 3.

Tabela 3

Comparação das Médias do Índice de Proeminência Facial (IPF) da Variável Humor Entre os Gêneros Feminino e Masculino

\begin{tabular}{ccccccc}
\hline \multirow{2}{*}{ HUMOR } & \multicolumn{2}{c}{ FEMININO } & \multicolumn{2}{c}{ MASCULINO } & \multicolumn{2}{c}{ ESTATÍSTICA } \\
\cline { 2 - 7 } & IPF & $\mathbf{N}$ & IPF & N & $\boldsymbol{F}$ & $\boldsymbol{p}$ \\
\hline Extrovertido/Extravagante & 0,5712 & 183 & 0,6418 & 161 & 10,330 & $0,001^{*}$ \\
Inteligente/Sagaz & 0,5878 & 155 & 0,6376 & 195 & 5,135 & $0,024^{*}$ \\
Misterioso & 0,5745 & 86 & 0,6141 & 110 & 1,897 & 0,170 \\
Pateta/Palhaço & 0,6231 & 43 & 0,6735 & 101 & 1,929 & 0,167 \\
Rude & 0,6153 & 9 & 0,6477 & 32 & 0,143 & 0,707 \\
Seco/Sarcástico & 0,5859 & 26 & 0,6714 & 64 & 4,200 & $0,043^{*}$ \\
Simpático & 0,5827 & 250 & 0,649 & 244 & 14,086 & $0,001^{*}$ \\
\hline
\end{tabular}

Nota. Os valores de $F$ correspondem à análise de variância.

* Valores significativos para $p<0,05$.

A partir dos resultados encontrados na Etapa I para as categorias de humor, a Etapa II buscou ampliar as análises comparando as médias do IPF entre pessoas de mesmo gênero que colocaram uma determinada categoria em relação às que não colocaram. Os resultados foram significativos apenas para a categoria "misterioso" entre o sexo masculino, sendo $66,1 \%$ o índice de proeminência facial para aqueles que não colocaram a categoria "misterioso" e $60,9 \%$ para quem a colocou $\left(F_{1,198}=4,817 ; p=0,007\right)$.

\section{DISCUSSÃO}

Conforme apresentação dos resultados pode-se afirmar que a pesquisa permitiu uma avaliação quantitativa exploratória acerca de diferenças de sexo, faixa etária, grau de instrução e humor em diversas dimensões investigadas. No que diz respeito a diferenças sexuais os resultados corroboraram com estudos anteriores que investigaram fotos impressas (Archer \& cols., 1983; Lapini, 2006; Zuckerman, 1986), na internet (Konrath \& Schwarz 2007; Szillis \& Stahlberg, 2007), assim como no próprio Orkut (Mansur \& cols., 2007) onde se verifica que os homens normalmente estabelecem uma maior proporção facial em fotos apresentadas. Tal peculiaridade vem sendo explicada pela atribuição de características "cerebrais" aos homens e "corporais" ou emocionais às mulheres. $\mathrm{O}$ fato de se atribuir maior dominância (Zuckerman, 1986) a fotos com elevado índice de proeminência facial pode ser um indicativo de que essa atribuição pode ser procurada pelos homens em geral.

Quando se comparou a faixa etária entre homens e mulheres, a única estatisticamente diferente foi de 20 a 24 anos com quase 17\%. Explicações para este fenômeno sem dúvida não podem descartar o papel significativo da cultura e dos aspectos biológicos envolvidos. Ainda que não tenha nenhuma explicação concreta na literatura, o início da idade adulta poderia significar a necessidade de assumir os papéis sexuais difundidos pela cultura. A escolha dos parceiros nesse período é muito comum e, pode ser explicada pelo amadurecimento biológico e maior desempenho físico e intelectual. Segundo Fernandes e Barros (2000), o pico da fertilidade feminina ocorre aos 20 anos, diminuindo de forma gradual ao longo dos anos. Percebese, com isto, que o pico da fertilidade feminina acontece exatamente na mesma faixa etária em que há maiores diferenças da proeminência facial entre homens e mulheres. Isto explicaria a necessidade de a mulher evidenciar mais sua atratividade corporal em detrimento dos aspectos intelectuais, como precisa fazer o homem no caso de mostrar sua capacidade de cuidar e sustentar seus descentes. Conforme vão se passando os anos e, assim, a redução da fertilidade feminina se torna mais aparente, a valorização corpo- 
ral vai perdendo espaço para outras finalidades e projetos de vida, podendo explicar o aumento da proeminência facial com a progressão da idade conforme mostra o estudo de Szillis e Stahlberg (2007). Entre os homens, considerando-se normalmente seu interesse em encontrar ou impressionar mulheres mais jovens podem adotar uma estratégia de valorização corporal, uma vez que possivelmente já se estabilizaram social e economicamente.

Quanto aos níveis de escolaridade, foram encontradas diferenças significativas entre o ensino médio e o ensino superior apenas para mulheres. Podemos levantar a hipótese de que quanto maior o grau de instrução, a mulher precisa se mostrar menos passiva e, portanto, mais confiante, dominante. Isso pode estar relacionado com a recente inserção feminina no mercado de trabalho que exigiu e ainda exige um alto grau de independência e dominância, representada por maior proeminência facial do que as mulheres com ensino médio. O fato de os dados não apresentarem diferença significativa para o grupo masculino pode nos levar à hipótese de que, independentemente do grau de instrução, o homem precisa carregar uma característica dominante em vista dos papéis sociais que lhe foram atribuídos ao longo da evolução da espécie e da sociedade.

Portanto, aqui parece estar envolvido outro critério de análise: as diferenças na proeminência facial podem estar relacionadas, não ao fator gênero em si, mas à questão de atribuição de papéis sociais que não necessariamente precisam ser análogas ao papel sexual. Assim, tanto uma mulher quanto um homem podem assumir um papel social dominante ao longo da sua vida quanto um papel cordial ou passivo, ainda que o mais comum e difundido seja homens com características dominantes e mulheres cordiais.

Considerando-se as características de humor autoatribuídas pelos usuários do Orkut, verificaram-se várias diferenças de gênero sugestivas de papéis sexuais diferenciados, estabelecidos em parte ao longo da história evolutiva da humanidade e em parte por aspectos culturais. Segundo Negreiros e Carneiro (2004), os papéis masculino e feminino configurariam tipificações do que seria pertinente ao homem e a mulher num dado contexto, englobando aprovações, restrições e proibições que seriam apreendidas e transmitidas ao longo de gerações e durante o percurso da vida. De maneira geral, a freqüência de usuários femininos e masculinos em cada categoria já direciona um indicativo dessas diferenças de gênero. Mais mulheres do que homens colocaram as categorias Extroverti-
do/Extravagante e Simpático, enquanto mais homens do que mulheres colocaram as categorias Inteligente/ Sagaz, Misterioso, Pateta/Palhaço, Rude e Seco/Sarcástico.

As categorias de maior frequência do sexo feminino apontam características mais voltadas para o social como ser simpática e ser extrovertida, isto é, aberta a outras pessoas. Ao contrário, nos homens, as categorias de maior frequência denotam um conteúdo menos emocional e mais racional como inteligência, sagacidade, mistério (como se não fosse possível acessar seus conteúdos emocionais), rudeza e sequidão. Ainda que não sejam exatamente as mesmas características utilizadas no estudo de Zuckerman (1986), Lapini e Caramaschi (2006), estas convergem para um mesmo conteúdo: emocional ou racional, o que implica dizer que neste estudo com fotografias do Orkut, as mulheres também se divulgam como mais ligadas ao emocional, enquanto os homens apresentam características mais relacionadas ao racional e ao intelecto.

$\mathrm{O}$ fato dos homens se caracterizarem mais frequentemente como Inteligentes/Sagazes corrobora com dados da literatura indicativos de que essa dimensão pesa consideravelmente quando as mulheres escolhem seus parceiros (Miller, 2001). Dessa forma, a maior proeminência facial dos homens estaria enfatizando suas características intelectuais, capazes de prover o sustento da família, em detrimento de seu aspecto corporal. O contrário se verifica nas mulheres nas quais a questão da atratividade corporal contribui mais fortemente na seleção de parceiros. A característica Seco/Sarcástico foi pontuada mais fortemente pelos homens, aparentemente indicando uma informação indireta de masculinidade, com menor dimensão emocional, mas ao mesmo tempo capaz de apresentar senso de humor, ainda que sarcástico. Existem evidências na literatura (Miller, 2001) de que o senso de humor pode ser um indicativo indireto de inteligência, uma característica muito valorizada nos homens.

O item Simpático foi o mais assinalado tanto pelos participantes masculinos quanto femininos. Os homens com essa característica, entretanto, diferem significativamente das mulheres no que diz respeito à proeminência facial. A maior proporção facial produz uma maior sensação de proximidade psicológica (Hall, 1989), dessa forma deve-se esperar que os homens se exponham mais a possíveis observadores, enquanto que as mulheres permanecem em atitude de maior afastamento e timidez.

A escassez de pesquisas nesta área impossibilita que todas as hipóteses supracitadas sejam afirmadas. 
Além disso, é importante destacar que diversas outras variáveis podem influenciar os dados apresentados como a necessidade de os usuários estarem sempre acessíveis e encontráveis, o fato de a imagem exposta ter sido retirada por outra pessoa, bem como modificada por recorte e/ou aproximação. No entanto, é possível afirmar, segundo Skinner (1984), que qualquer comportamento é produto de três níveis de seleção: o filogenético (história da espécie), o ontogenético (história particular de vida do indivíduo, condicionamento operante ou seleção por reforçamento) e o cultural (história das práticas culturais). Cavalcante (1997) faz a seguinte consideração:

Dentro desta ótica, o comportamento seria produzido pela atuação conjunta dos três níveis de contingências (filogenéticas, ontogenéticas e culturais). $\mathrm{O}$ autor argumenta, ainda, que o fenômeno comportamental só será conhecido, em todas as suas dimensões, com a reunião dos saberes produzidos pela 'Etologia', pela 'Fisiologia', por uma parte da 'Antropologia' e pela própria Análise do Comportamento (...) Cada disciplina científica deveria, então, definir o recorte que melhor teria competência metodológico-instrumental para estudar. Assim, ter-se-ia na partilha do 'bolo comportamental' feita por Skinner (...) a Etologia, investigando as contingências filogenéticas, a Análise do Comportamento, investigando as contingências ontogenéticas e a Antropologia (ou 'uma parte dela', pelo menos), investigando as contingências culturais. (pp. 76-77)

$\mathrm{O}$ intuito deste estudo não foi definir uma linha fechada de análise, mas sim, reunir a contribuição das diversas ciências para ampliar a investigação sobre Proeminência Facial. Portanto, além dos possíveis aspectos biológicos envolvidos, não se pode desmerecer o fato de o corpo feminino e o status social masculino ser culturalmente difundidos, aceitos e valorizados uma vez que a cultura assume um papel fundamental na construção e desempenho dos papéis sexuais e sociais. Ainda que atualmente a estrutura social tenha ampliado os papéis de ambos os gêneros, é importante lembrar que há muitas características e comportamentos que diferenciam homens e mulheres. De acordo com os dados apresentados em estudos internacionais, nacionais e nesta pesquisa, o comportamento de fotografar-se parece ser um indicativo de diferença entre gêneros. A aceitação pessoal e social da estética tem sido extremamente valorizada em diversas sociedades, inclusive a brasileira. Os diversos meios de comunicação divulgam imagens inseridas em padrões de beleza altamente almejadas. Portanto, a cultura é um componente importantíssimo na orientação dos comportamentos uma vez que carrega as normas, regras, valores e crenças.

Apresentar-se mais próximo ou mais distante pode revelar muito de uma pessoa já que, como dito anteriormente, o comportamento carrega elementos da história filogenética, ontogenética e cultural. Ainda que cada fotografia carregue suas particularidades parece, segundo Levesque \& Lowe (1999), que as diferenças na proeminência facial entre os gêneros, observadas nos meios de comunicação, contribuem para reforçar estereótipos construídos ao redor dos papéis sociais ao longo da história.

\section{REFERÊNCIAS}

Archer, D., Iritani, B., Kimes, D. D., \& Barrios, M. (1983). Faceism: Five studies of sex differences in facial prominence. Journal of Personality and Social Psychology, 45, 725-735.

Bretl, D. J., \& Cantor, J. (1988). The portrayal of men and women in US television commercials: A recent content analysis and trends over 15 years. Sex Roles, 18, 595-609.

Campos, F. K., \& Gomes, C. F. (2009). O corpo nos espaços públicos cuiabano: Um estudo etológico de seu comportamento. Revista Digital, 14. Retirado em 26 de agosto de 2009, de http://www.efdeportes.com/efd133/o-corpo-nos-espacospublicos-um-estudo-etologico.html

Caramaschi, S. (1997). Proxêmica: O significado psicológico e cultural do espaço. Em Sociedade Brasileira de Etologia (Org.), Anais do XV Encontro Anual de Etologia (pp. 155-167), São Carlos, SP: SBE.

Cavalcante, S. N. (1997). Abordagem biocomportamental: Síntese da análise do comportamento? Psicologia: Reflexão e Crítica, $10,263-273$.

Copeland, G. A. (1989). Face-ism and primetime television. Journal of Broadcasting \& Electronic Media, 33, 209-214.

Dornelles, J. (2004). Antropologia e internet: Quando o "campo" é a cidade e o computador é a "rede". Horizontes Antropológicos, 10, 241-271.

Fernandes, K., \& Barros, S. M. O. (2000). Avaliação do perfil reprodutivo dos casais assistidos no setor de reprodução da Universidade Federal de São Paulo. Acta Paulista de Enfermagem, 13 (Número Especial), Parte II, 70-72.

Hall, E. (1989). A dimensão oculta (S. Coutinho, Trad.). Rio de Janeiro: Francisco Alves.

Honorato, E. J. S. (2006). Comunidade virtual Orkut: Uma análise psicossocial. Em O. Z. Prado, I. Fortim, \& L. Cosentino (Orgs.), Psicologia \& informática: Produções do III Psicoinfo e II Jornada do NPPI (pp. 31-47). São Paulo: Conselho Regional de Psicologia de São Paulo.

Knapp, M., \& Hall, J. (1999). A comunicação não-verbal na interação humana. São Paulo: JSN.

Konrath, S. H., \& Schwarz, N. (2007). Do male politicians have big heads? Face-ismin online self-representations of politicians. Media Psychology, 10, 436-448.

Lapini, D. T., \& Caramaschi, S. (2006). A proporção facial em revistas brasileiras e suas implicações. Em Departamento de 
Psicologia da UNESP-Bauru (Org.), Anais do I Congresso de Psicologia. Bauru: UNESP.

Levesque, M. J., \& Lowe, C. A. (1999). Face-ism as a determinant of interpersonal perceptions: The influence of context on facial prominence effects. Sex Roles. 41, 241-259.

Lima, I. (1988). A fotografia e a sua linguagem. Rio de Janeiro: Espaço e Tempo.

Luccio, F., \& Nicolaci-da-Costa, A. M. (2010). Blogs: De diários pessoais a comunidades virtuais de escritores/leitores. Psicologia: Ciência e Profissão, 30, 132-145.

Mansur, C. M., Santos, L. Q. L., Rimoldi, L. P., Silva, V. V. P., \& Caramaschi, S. (2007). Proeminência facial nas fotos do Orkut: Comparação entre gêneros. Em UNESP-Araraquara e PROPe (Orgs.), Anais do XIX Congresso de Iniciação Científica da UNESP. Araraquara: UNESP.

Matthews, J. L. (2007). Hidden sexism: Facial prominence and its connections to gender and occupational status in popular print media. Sex Roles, 57, 515-525.

Miller, G. F. (2001). A mente seletiva: Como a escolha sexual influencia a evolução da natureza humana (D. Batista, Trad.). Rio de Janeiro: Campus.

Negreiros, T. C. G. M. \& Féres-Carneiro, T. (2004). Masculino e feminino na família contemporânea. Estudos e Pesquisas em Psicologia, 4, 34-47.

Nicolaci-da-Costa, A. M. (2005). Sociabilidade virtual: Separando o joio do trigo. Psicologia \& Sociedade, 17, 50-57.
Nigro, G. N., Hill, D. E., Gelbein, M. E., \& Clark, C. L. (1988) Changes in the facial prominence of women and men over the last decade. Psychology of Women Quarterly, 12, 225-235.

Ortiz, R. (1999). Um outro território: Ensaios sobre a mundialização. São Paulo: Olho D’Água.

Schwarz, N., \& Kurz, E. (1989). What's in a picture? The impact of face-ism on trait attribution. European Journal of Social Psychology, 19, 311-316.

Silva, M. F., Silva, M. J. P., \& Menezes, M. A. J. (2006). Análise dos fatores proxêmicos na interação dos profissionais de saúde com os pacientes queimados. Revista Paulista de Enfermagem, $25,4-10$.

Skinner, B. F. (1984). Selection by consequences. The Behavioral and Brain Sciences, 7, 477-481.

Szillis, U., \& Stahlberg, D. (2007). The face-ism effect in the internet: Differences in facial prominence of women and men. International Journal of Internet Science, 2, 3-11.

Zuckerman, M. (1986). On the meaning and implications of facial prominence. Journal of Nonverbal Behavior, 10, 215-229.

Zuckerman, M., \& Kieffer, S. C. (1994). Race differences in face-ism: Does facial prominence imply dominance? Journal of Personality and Social Psychology, 66, 86-92.

Recebido: 09/04/2010

Última revisão18/07/2011

Aceito: $30 / 07 / 201$ 